led him to modify his views in several ways. As it is, his preface is dated from Faizabad, and in it he describes himself as "a solitary Indian, far away from contact with men of science, but fresh from the actual and impressive presence of 'Nature's children.'" These words account for the freshness and vigour of his style, but they must not be taken to imply that his examination was made without want of knowledge of anthropology. So far from this, one of the great excellencies of the volume lies in showing how much more deeply an observer sees into the life of an uncivilised people, when he is engaged in examining evidence for and against current ethnological theories, than when he goes as a mere traveller, setting down at random anything that takes his attention.

\section{EDWARD B. TYLOR}

\section{OUR BOOK SHELF}

An Elementary Treatise on Geometrical Conic Sections. By G. Richardson, M.A. (Rivington, I873.)

THIs is one of the volumes of the publisher's Mathematical Series, is very well printed, and has, if we are not mistaken, only three trivial misprints. There is quite a run at the present time on this subject, if we may judge by the number of treatises which have recently made their appearance, and this we are not altogether surprised at, as it is one of great interest; its theorems have great intrinsic beauty and almost boundless applications. The ordinary propositions are discussed not altogether in the usual order of consecution from the locus-point of view (the last chapter of four pages being devoted to the cone); the demonstrations are neat, and two or three are exceedingly concise as well. The only or chief novelty is the simultaneous treatment of the ellipse and the hyperbola, the corresponding propositions facing one another on the even and odd pages respectively. The discussion of the asymptotic properties of the latter curve pairs off against a series of propositions on projections. The book is a good working one for beginners, and embraces sufficient for the preliminary examination for mathematical honours at Cambridge, without having too much for school use. There is an extensive selection of exercises.

R. T.

Waste Products and Undeveloped Substances. A Synopsis of progress made in their economic utilisation during the last quarter of a century, at home and abroad. By P. L. Simmonds. (London: Hardwicke, 1873.)

MR. SIMMONDS'S book is seasonable in these days, when so much has been done in the utilisation of waste, as showing how very much yet remains to do.

In nearly 500 pages of close print he has drawn attention to a mass of matter almost bewildering in its vastness, and extending to nearly every kind of material in use in civilised communities. We cannot help noticing that Mr. Simmonds has been affected by the mass of subjects he has attempted, for the book very frequently displays a considerable lack of arrangement.

The author should look to this in a future edition, in which also the book might be easily and advantageously condensed to a considerable extent.

We must, however, thank the author for the service he does in calling the attention of civilisation to the extravagant, and we might say, "riotous" living with which its substance is wasted.

La Botanique de la Bible. Étude scientifique, historique, litteraire et exégétique des plantes mentionnées dans la Sainte-Ecriture. Par Frédéric Hamilton. 8vo. pp. 220, 25 photographs. (Nice: Eugène Fleurdelys, I87I.)

THIS interesting volume will possibly be unknown to the majority of our readers, and yet we venture to think that, from the beauty of its illustrations and the pleasantness of its style, it may to some of them prove a welcome addition to their knowledge of the subject on which it treats. Not stopping to discuss the nature of those mysterious trees said to have existed in the Garden of Eden, the author divides his subject into two parts. The first treating of the genera and species of which there can be little doubt, such as the pomegranate, almond, cedar, fig, $\&$ c. ; and the second of those plants or portions of plants about which it is difficult to decide to what genus even they may belong, such as shittim-wood, hyssop, \&c. In the first portion of the volume not only are the scientific characters of the plants given, but there is also added a series of references to them from the classics. The photographs are taken from living specimens growing chiefly in the neighbourhood of Nice and Mentone.

\section{LETTERS TO THE EDITOR}

[The Editor does not hold himself responsible for opinions expressed by his correspondents. No notice is taken of anonymous conmunications.]

\section{Effects of Temperature on Reflex Action}

I Do not know if I quite understand Mr. Lewes's objections to my little article in the Foumal of Anatomy and Physio. $\log y$. He attributes the absence of movements in the case in question to a loss of sensibility to temperature. At first his statement reads as if the loss of sensibility to temperature were due to the removal of the brain. But he cannot mean this, because the whole of my paper starts from the fact that when the toes alone are exposed to gradually heated water, the leg is withdrawn. If he means that the sensibility to temperature alone is destroyed or depressed by the exposure of the whole body to the gradually heated water, and the other "sensibilitics" left intact, I do not see how my argument touching the difference between the entire and the brainless frog is affected at all by a limitation of the stimulus to one particular kind. Moreover, in the last observation recorded in my paper it is expressly stated that in the later stages of heating the absence or diminution of reaction towards chemical as well as thermal stimuli was observed. Gradually heated water acts as a very slight stimulus, sulphuric acid (even dilute) is a very strong stimulus; and that the latter suddenly applied, as in the experiment of Golzz referred to by $\mathrm{Mr}$. Lewes, should call forth a reflex action at a time when the former is unable to do so, in no way contradicts my explanation of the absence of movements. A red-hot iron might have been substituted for the sulphuric acid with identical results.

The paper in question had for its object simply the solution of the difficulty why the brainless frog allowed himself to be boiled without moving. In it I carefully avoided entering upon any discussion concerning Sensation (or Consciousness) in the spinal cord. The words " movement of volition, that is, a movement carried out by the encephalon,"- "ordinary reflex action, that is, a movement carried out by the spinal cord alone," were purposely chosen. I went so far as to speak of an "intelligent frog" and an "unintelligent reflex action," because we have means of measuring intelligence, and we can speak of a body as being conscious and yet not intelligent. I imagine that if $\mathrm{Mr}$. Lewes and myself were to talk over the matter quietly, he would find that I am not so much at variance with him as he imagines. I feel with him the difficulty of refusing to the protoplasm of a white blood corpuscle, a something which may be evolved into (not out of) consciousness. That and like difficulties are not. a little increased if, as Mr. Darwin seems to suggest, we regard inherited voluntary acts as the chief instead of the occasional source of reflex actions. Without entering into any long discussion, perhaps I may be permitted to say that in such matters as the muvements of a brainless frog, it seems to me there are two things which ought to be kept separate : the investigation into the laws according to which those movements take place, $i, e$., the study of the various nervous mechanisms of the spinal cord, and the question whether those movements, whether the working of those mechanisms, is or is not accompanied by consciousness. As a physiologist I am prepared to busy myself with the first, as I see prospects of success. With regard to the second, I an not prepared to say anything until we have ob. 